\title{
Between being healthy and becoming comatose: the neuropsychiatric landscape of critical illness with a focus on delirium, DSM-5 and ICD-11
}

\author{
Jan N. M. Schieveld ${ }^{1,2}$, Emma H. C. W. van de Riet ${ }^{1,2}$ and Jacqueline J. M. H. Strik ${ }^{1,2^{*}}$ (D)
}

\begin{abstract}
Background: One of the most important questions remaining in matters of critical illness in the year 2019 is arguably how to address the diverse neuropsychiatric complications of critical illness.

Main text: The ICD-11 and DSM-5, two of the world's leading classification systems, disagree regarding important aspects of delirium; moreover, they do not mention critical illness and its neuropsychiatric complications at all.

Conclusions: It would have been desirable for the committees revising the DSM-IV-TR and ICD-10 to have joined forces in order to generate classification systems that complement each other and, moreover, that address the "The Neuro-Psychiatry of Critical IIIness".
\end{abstract}

Keywords: Neuropsychiatry, Delirium, Critical illness, ICD-11, DSM-5

\section{Background}

The number of intensive care unit (ICU) admissions annually due to critical illness, and the associated mechanical ventilation episodes and days, is one of the fastest growing numbers in clinical medicine in the western world. Critical illness can cause the brain to react in the form of disruptive neuropsychiatric symptoms and disorders, the most well-known being delirium. As early as 1980, ZJ Lipowski stated: "Delirium is acute brain failure in man" [1]. This awareness is important, as a healthy brain, which also directs the autonomic nervous system and endocrine systems, is crucial in surviving critical illness.

\section{Main text}

The ten most common neuropsychiatric reaction types of the brain are: fever, sickness behavior, executive function problems, epilepsy, hyperactive delirium, acute

\footnotetext{
* Correspondence: j.strik@mumc.nl

'Department of Psychiatry and Psychology, Division of Child and Adolescent Psychiatry and Psychology, Maastricht University Medical Center, P.O. Box 5800, 6202, AZ, Maastricht, The Netherlands

${ }^{2}$ School for Mental Health \& Neuroscience (MHeNS), University of Maastricht, Maastricht, The Netherlands
}

(c) The Author(s). 2019 Open Access This article is distributed under the terms of the Creative Commons Attribution 4.0 International License (http://creativecommons.org/licenses/by/4.0/), which permits unrestricted use, distribution, and reproduction in any medium, provided you give appropriate credit to the original author(s) and the source, provide a link to the Creative Commons license, and indicate if changes were made. The Creative Commons Public Domain Dedication waiver (http://creativecommons.org/publicdomain/zero/1.0/) applies to the data made available in this article, unless otherwise stated. 
mortality) and in the long run the final level of psychosocio-emotional functioning. Unfortunately, many survivors of critical illness suffer from brain injury (non-traumatic), post-traumatic stress disorder (PTSD), anxiety, or depression, as do many of their family members [4]. Lastly, the burden of these symptoms also involves huge medical and non-medical costs.

So how can we make sense of this very complicated yet clinically highly important variable and fluctuating neuropsychiatric landscape? And how can we get a quick and easy overview of all these neuropsychiatric reaction types of the brain at the patient' bedside?

One step forward is the introduction of the ABCDEF bundle [5]. This is an evidence-based guide for all medical and paramedical specialists and nursing teams alike to develop and approach the multidisciplinary organizational changes required for optimizing ICUpatient recovery and outcomes. The ABCDEF bundle includes: Assess, prevent, and manage pain; organize both spontaneous awakening and spontaneous Breathing and organize multidisciplinary Brain rounds; organize well-considered Choice of analgesia and sedation; assess, prevent, and manage Delirium; assess and manage Early mobility and Exercise; and organize Family empowerment and engagement [5].

However, neither the fifth edition of the diagnostic and statistical manual of mental disorders (DSM-5) nor the recently published and yet to be adopted eleventh revision of the international classification of diseases (ICD-11), the number one classification system in the world, hardly mention or do not mention at all neuropsychiatric symptoms and disorders in the critically ill $[6,7]$. There are discrepancies between DSM-5 and the ICD-11regarding delirium, especially regarding the existence of the three delirium motor types: hyper-"hypo"(acute apathy syndrome) and mixed. This clinically highly important distinction is made in the DSM- 5 but not in the ICD-11. Moreover, the DSM-5 and the ICD 11 share the same major flaw: they appear to disregard the existence of the concept of critical illness entirely, and this is truely concerning. The DSM-5 only mentions the existence of "intensive care" once, on page 600, and this is in relation to the very high prevalence of delirium there, while the ICD-11 does not contain the search terms "critical illness" at all.

Specifically, they do not discuss sickness behavior, executive function problems, or acute apathy syndrome, nor do they agree about some major issues relating to delirium such as: 1) which criteria are necessary? (e.g. illness/critical illness, level of consciousness, sickness behavior, and/or executive function problems); 2) which criteria are sufficient (plus an agitation and/or inhibition syndrome)?; 3) which subtypes of delirium exist? and 4) which are the main type-specifying criteria? [8] (Fig. 1).

Addressing these questions is of ever-growing clinical relevance [8]. This is also illustrated by a very recent paper in which the authors treated "delirium with antipsychotics" [9]. However, as they did specify the delirium type, they next did not specify the unique targeted symptoms by the antipsychotics $[1,10]$. Specifying the delirium type is important, as acute apathy syndrome differs from hyperactive delirium in four major aspects: its symptoms, its prevalence (higher), the treatment response (lower/none), and the outcome (worse) [2].

\section{Conclusions}

It would have been logical for the committees revising the DSM-IVTR and ICD-10 to have joined forces in order to generate classification systems that complement each other and, moreover, that address the aforementioned issues in a section entitled "The Neuro-Psychiatry of Critical Illness". This section will be highly relevant for medical and non-medical specialists, patients, their families, and other parties. It will direct future scientific research, enhance awareness and understanding of neuropsychiatric symptoms and disorders in the critically ill, and thus improve patient and family care, outcomes, and well-being.

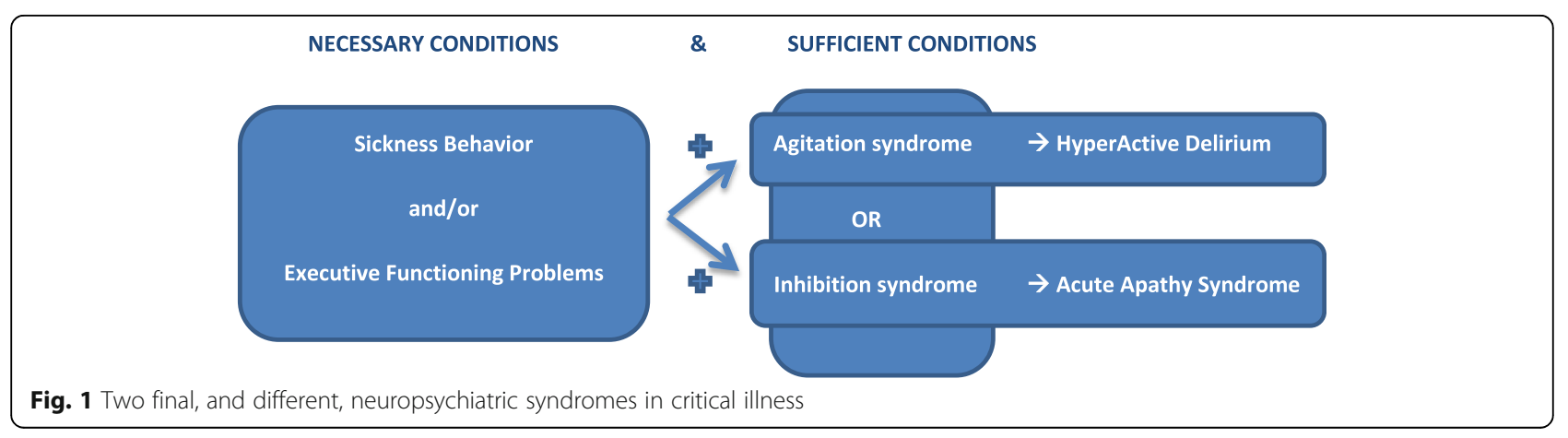




\section{Abbreviations}

DSM-5: fifth edition of the diagnostic and statistical manual of mental disorders; ICD-11: eleventh revision of the international classification of diseases; ICU: Intensive care unit; PTSD: Post-traumatic stress disorder;

RASS: Richmond Agitation-Sedation Scale

\section{Acknowledgements}

We kindly acknowledge Ms. Jolien Nivelle of MUMC+ for her support in the layout of Fig. 1.

\section{Authors' contributions}

JS1 and JS2 produced the first draft together; EvdR contributed to the various versions of subsequent drafts as well as to the final version. All authors read and approved the final manuscript.

\section{Funding}

There are no funding sources.

Availability of data and materials

Not applicable.

Ethics approval and consent to participate

Not applicable.

\section{Consent for publication}

Not applicable.

\section{Competing interests}

The authors declare that they have no competing interests.

Received: 18 April 2019 Accepted: 30 June 2019

Published online: 16 July 2019

\section{References}

1. Lipowski ZJ. Delirium - acute brain failure in man. Charles C Thomas, Springfield IL; 1980.

2. Schieveld JNM, Strik JJMH. Hypoactive delirium is more appropriately named as "acute apathy syndrome". Crit Care Med. 2018;46:1561-2.

3. Sessler CN1, Gosnell MS, Grap MJ, et al. The Richmond agitation-sedation scale: validity and reliability in adult intensive care unit patients. Am J Respir Crit Care Med 2002;166:1338-1344.

4. Girard TD, Dittus RS, Ely EW. Critical illness brain injury. Annu Rev Med. 2016;67:497-513.

5. Marra A, Ely EW, Pandharipande PP, et al. The ABCDEF Bundle in Critical Care. Crit Care Clin. 2017;33:225-43.

6. World Health Organization. International statistical classification of diseases and related health problems (11th Revision); https://icd.who.int/browse11/l-m/en. Accessed 10 Apr 2019.

7. American Psychiatric Association. Diagnostic and statistical manual of mental disorders: DSM-5. Arlington VA: American Psychiatric Publishing; 2013.

8. Strik JJMH, Schieveld JNM. Prophylactic Haloperidol for Critically III Adults. JAMA. 2018;320:303.

9. Girard TD, Exline MC, Carson SS, et al. Haloperidol and ziprasidone for treatment of delirium in critical illness. N Engl J Med. 2018;379:2506-16.

10. Bleck TP. Dopamine Antagonists in ICU Delirium. N Engl J Med. 2018:379:2569-70.

\section{Publisher's Note}

Springer Nature remains neutral with regard to jurisdictional claims in published maps and institutional affiliations.

Ready to submit your research? Choose BMC and benefit from:

- fast, convenient online submission

- thorough peer review by experienced researchers in your field

- rapid publication on acceptance

- support for research data, including large and complex data types

- gold Open Access which fosters wider collaboration and increased citations

- maximum visibility for your research: over $100 \mathrm{M}$ website views per year

At $\mathrm{BMC}$, research is always in progress.

Learn more biomedcentral.com/submissions 